\title{
TESTING THE SIMILARITY FIT/MISFIT HYPOTHESIS IN ADOLESCENTS AND PARENTS WITH ADHD
}

\author{
by
}

Teresa Grimbos

A thesis submitted in conformity with the requirements for the degree of Master of Arts

Graduate Department of Applied Psychology and Human Development

Ontario Institute for Studies in Education

University of Toronto

(C) Copyright by Teresa Grimbos 2014 


\title{
TESTING THE SIMILARITY FIT/MISFIT HYPOTHESIS IN ADOLESCENTS AND PARENTS WITH ADHD
}

\author{
Master of Arts, November 2014 \\ Teresa Grimbos \\ Department of Applied Psychology and Human Development \\ University of Toronto
}

\begin{abstract}
Parents and adolescents with ADHD may engage in excessive conflict due to the nature of adolescent ADHD behaviours (impulsivity, inattention) and the difficulties associated with parenting them. This may be magnified when parents struggle with ADHD and when comorbid adolescent externalizing problems exist. Despite the logic of an exacerbative effect when adolescents and parents have ADHD, research suggests that parents with ADHD show more tolerance, empathy and less conflict with their children who share similar cognitive traits (i.e., similarity-fit hypothesis). This study tested the similarity-fit/misfit hypotheses in a sample of 156 adolescents (mean age $=15.25)$ and their parents. Results supported the similarity-fit process in fathers whereby fathers and adolescents with higher inattention levels engaged in fewer conflicts. In mothers, the similarity-misfit hypothesis was supported: frequency of conflict was highest when mothers and adolescents had highest levels of inattention. Results were interpreted in the context of gender and parental roles.
\end{abstract}




\section{Acknowledgements}

I wish to thank my supervisor, Dr. Judith Wiener, for her excellent support during my clinical degree and towards this thesis. I also thank Dr. Jennifer Jenkins for her always superb feedback regarding my work. I also want to take this opportunity to thank Dr.'s Sandy Simpson and Stephanie Penney, my supervisors at the Centre for Addiction and Mental Health (Complex Mental Illness, Forensic Division). I thank them for the opportunity to continue working while studying and also for their support and encouragement as I carried both work and school responsibilities. I cannot exclude a shout-out to my friends who have kept me sane with constant jokes, dance parties and concert outings. Last but definitely not least, I want to thank my incredible family (Mom, Dad, Baba, Grimbos family) for showering me with love and laughter throughout my life, and for always being supportive of my goals and dreams. You guys rock! 


\section{TABLE OF CONTENTS}

$\begin{array}{lr}\text { Abstract } & \text { ii } \\ \text { Acknowledgements } & \text { iii } \\ \text { Introduction } & \mathbf{1} \\ \text { Adolescents with ADHD and adolescent-parent conflict } & 2 \\ \text { Parental ADHD and parenting } & 4 \\ \text { The current study } & 7 \\ \text { Method } & \mathbf{9} \\ \text { Participants } & 9 \\ \text { Measures } & 11 \\ \text { Procedure } & 12 \\ \text { Data Analysis } & 13 \\ \text { Results } & \mathbf{1 4} \\ \text { Bivariate correlations } & 14 \\ \text { Adolescent and maternal ADHD symptoms as predictors of adolescent-parent... } & 15 \\ \text { Adolescent and paternal ADHD symptoms as predictors of adolescent-parent... } & 16 \\ \text { Discussion } & \mathbf{1 7} \\ \text { Limitations } & 21 \\ \text { Conclusions, future directions and clinical implications } & 22 \\ \text { References } & \mathbf{2 4} \\ \text { Tables } & \mathbf{3 2} \\ \text { Figures } & \mathbf{3 8}\end{array}$




\section{Introduction}

The current study examines adolescent-parent conflict in a community sample of adolescents and their parents, both with varying levels of ADHD symptomatology. Our goal was to study the interaction between adolescent and parental ADHD in order to test whether similarity-fit or similarity-misfit processes occur within families with adolescents who have ADHD. The similarity-fit model posits that parents with ADHD are more understanding and tolerant towards their child with ADHD, thus contributing to more positive parenting behaviours. The similarity-misfit model proposes that parental ADHD exacerbates the challenges associated with raising a child with ADHD. Given the extent and severity of comorbid problems evident in adolescents with ADHD (Rohde et al., 1999), it is important to study this developmental period to better understand and think about factors related to prevention and intervention. Adolescence may also be an important context for testing the similarity-fit and misfit hypotheses because adolescent manifestations of ADHD may appear more similar (compared to manifestations in childhood) with those expressed by their adult parents. The current study investigates adolescent-parent conflict, an ideal outcome to study because adolescence is a critical period for youth and their parents, with increased conflict and stress within families during this time, especially for ADHD youth (Barkley, Anastopoulos, Guevremont \& Fletcher, 1992; Markel \& Wiener, 2014; Barkley, Fischer, Edelbrook \& Smallish, 1991). Adolescent-parent conflict may thus be a salient and relevant process to study in this population. Conflict is also a key outcome to examine as it directly and indirectly taps into the very processes proposed to be at play in the similarity-fit hypothesis (e.g., less conflict, higher tolerance, patience and understanding). 


\section{Adolescents with ADHD and adolescent-parent conflict}

Parents and adolescents experience much friction as youth struggle to establish independence from their parents who often have different expectations about appropriate timing of autonomy (Van Doorn, Branje \& Meeus, 2008; Steinberg \& Morris, 2001). It can be surmised that adolescents with ADHD would show even greater discordance with their parents on the account of the very symptoms of their disorder, namely impulsivity, difficulties with inattention and self-regulation. Indeed, studies have demonstrated more conflict between adolescents with ADHD and their parents, compared to typically developing adolescents and their parents (Barkley, Fischer, Edelbrook \& Smallish, 1991; Barkley, Anastopoulos, Guevremont \& Fletcher, 1992; Markel \& Wiener, 2014; Edwards, Barkley, Laneri, Fletcher \& Metevia, 2001; Fletcher, Fischer, Barkley \& Smallish, 1996). Research, examining both reports of conflict as well as observations of parent-child interactions, supports that ADHD youth and their parents engage in higher rates of conflict (Barkley et al., 1992; Markel \& Wiener, 2014), more intense conflict (Barkley et al., 1991) and more mutually negative behaviours during interactions (e.g., controlling behaviours; Edwards et al., 2001; Fletcher et al., 1996). This parentadolescent conflict is proposed to arise from academic and social problems evident in youth with ADHD, as well as other behaviours such as lying, defiance and noncompliance (Markel \& Wiener, 2014; Barkley et al., 1992).

Child and adolescent externalizing problems, often comorbid with ADHD (Barkley et al., 1991), are also strongly associated with conflict between parents and their children (Patterson, Reid \& Dishion, 1992; Ingoldsby et al., 2006). The oppositional, argumentative and irritable behaviours in externalizing children and youth are considered 
to elicit negative behaviours and conflictual reactions from parents. Many of the aforementioned studies comparing ADHD families versus comparison families also identified that comorbid oppositional defiant disorder (ODD) symptoms either accounted for most of the variance or magnified the rate and intensity of conflict between parents and adolescents with ADHD (Edwards et al., 2001; Barkley et al., 1991; Fletcher et al., 2006). Barkley and colleagues (1992) demonstrated the importance of both adolescent ADHD and ODD symptoms on conflict rates and intensity.

The role of parents in conflict with adolescents is also an important factor to consider. Conflict can be exacerbated by the reactions of parents to adolescent negative behaviours, particularly evident in parents who struggle with psychopathology themselves (Fletcher et al., 1996; Edwards et al., 2001). Parents with ADHD may have most difficulty in coping and managing their youth's general behavior as well their behavior during conflict, thus amplifying the rate and intensity of conflict. Edwards and colleagues (2001) examined the role of parental psychopathology, including ADHD, on conflict with adolescents. In this study, the effect of adolescent symptoms as well as parental symptoms (e.g., hostility, anxiety, depression and ADHD) on adolescent-parent conflict was examined separately in mothers and fathers. Maternal hostility contributed to more conflict above and beyond adolescent ADHD and ODD. In fathers, hostility also contributed to higher conflict and paternal anxiety was related to less conflict with their teenager. Although parental ADHD did not affect conflict in this study, the results suggest that the type of parental psychopathology impacts on conflict with adolescents in different ways, and may be different in fathers and mothers. In a recent study by Babinski et al. (2012), the highest amount of conflict was reported by mothers with ADHD who 
also had an adolescent with ADHD. This was in comparison with mothers without ADHD who had an adolescent with ADHD, and with non-ADHD (i.e., control) dyads (Babinski et al., 2012)

\section{Parental ADHD and parenting}

Parenting difficulties can certainly impact conflict. Indeed, parents with ADHD show challenges in many aspects of parenting (Murray \& Johnston, 2006; ChronisTuscano, Raggi, Clarke, Ronney, Diaz \& Pian, 2008; Chen \& Johnston, 2007), and it is suggested that executive functioning deficits in ADHD (e.g., working memory, planning and inattention difficulties) are what make parenting such a challenge for these parents (Johnston, Mash, Miller \& Ninowski, 2012). Some studies have found that maternal inattention in particular was associated with more negative parenting; for example, inattentive mothers showed inconsistent discipline, deficits in monitoring, and were less positive and involved with their children (Chen \& Johnston, 2007; Murray \& Johnston). In a recent and comprehensive review of the literature, Johnston and colleagues (2012) pointed out some differences in findings across studies, namely that parental ADHD influences parenting differently depending on the parenting domain being measured. The authors overviewed several studies demonstrating that parents with ADHD showed challenges in parenting behaviours intended to direct or protect their child, such as more negative disciplinary practices (e.g., inconsistent discipline, lax parenting, over-reactive parenting, physical punishment), less structured and chaotic family environments and more criticism towards their children (Murray \& Johnston, 2006; Chronis-Tuscano et al., 2008; Harvey, Danforth, Eberherdt McKee, Ulaszek \& Friedman, 2003; Chen \& Johnston, 2007; Mokrova, O’Brien, Calkins \& Keane, 2010). These findings were across 
preschool and school-aged, clinical and community samples of children with and without ADHD. On the other hand, studies that examined more affective parenting processes showed no significant association between parental ADHD and warmth, sensitivity, positivity and emotional responsivity towards their children (Chen \& Johnston, 2007; Murray \& Johnston, 2006; Ellis \& Nigg, 2009; Mokrova et al., 2010). Noteworthy is the fact that most of these studies, with the exception of Murray and Johnston (2006), focused on community (i.e., non-ADHD) samples of children. Regarding mothers with ADHD and affective parenting with children with ADHD, it has been shown that mothers with higher levels of ADHD symptoms were more praising and positive during play with their ADHD children (Chronis-Tuscano et al., 2008), and were more likely to positively reinforce their ADHD children (Williamson, 2013). The latter author speculated that these mothers were more playful and gregarious and thus less frustrated by similar behaviours in their children.

Therefore, parenting domains do not appear to be equally affected by parental ADHD. To explain some of the null and positive effects for positive and responsive parenting, it may be that parents of adolescents with ADHD have greater tolerance for aversive behaviours. This may especially be the case for parents with ADHD themselves as they may develop a better understanding, tolerance and simpatico for their children who share similar attributes (i.e., similarity-fit hypothesis; Psychogiou, Daley, Thompson \& Sonuga-Barke, 2007; Psychogiou, Daley, Thompson \& Sonuga-Barke, 2008). This may be the reason why null effects were observed for some of the positive parenting studies that mostly investigated community (i.e., non-ADHD) samples. Thus, it seems important to consider how parental ADHD interacts with child ADHD symptoms. 
Among the small number of studies that have analyzed how parental ADHD moderates child ADHD, there is some preliminary evidence indicating that parental ADHD actually ameliorates the negative effects of child ADHD on parenting (Biederman et al., 2002; Psychogiou et al., 2007; 2008; Griggs \& Mikami, 2011). The similarity-fit hypothesis, an extension of the goodness-of-fit concept (Thomas \& Chess, 1977), was posited by Psychogiou and her colleagues in order to explain this effect (Psychogiou et al., 2007; 2008). Based on results from some of their studies, Psychogiou et al. (2007; 2008) suggested that parents with ADHD may be more understanding, empathic, tolerant and less frustrated with their children with ADHD who share similar traits and attributes. Furthermore, similarities with respect to motivations for behavior and "cognitive tempo" result in less conflict between parent and child. Studies have found that mothers with elevated levels of ADHD reported more positive involvement and showed more positivity and affection (Psychogiou et al., 2007; 2008) and were less irritable and less corrective (corrective was construed as a negative parenting behavior; Griggs \& Mikami, 2011) towards their children with higher levels of ADHD. In addition, mothers with higher levels of ADHD reported more negative parenting (e.g., inconsistent discipline, physical punishment, poor monitoring) towards children with fewer ADHD symptoms (Psychogiou et al., 2007; 2008). Notably, the similarity-fit hypothesis proposes less conflict when parents and adolescent both have ADHD; however, no studies have directly investigated this particular outcome.

On the other hand, the similarity-misfit hypothesis proposes that parental ADHD exacerbates the negative impact of child ADHD on parenting (Fischer, 1990; Psychogiou et al., 2007; Babinski et al., 2012). The limited research suggests thus far that this 
phenomenon may occur in fathers with ADHD (Psychogiou et al., 2007). Fathers with higher levels of ADHD reported more negative parenting towards their children who also had more ADHD symptoms (Psychogiou et al., 2007). The authors speculated that fathers may be more frustrated and overwhelmed by their child's ADHD behaviours whereas mothers are more likely to be empathic towards them. Although they did not examine a statistical interaction between child and paternal ADHD, Arnold, O'Leary and Edwards (1997) found that when involved fathers reported high levels of ADHD symptoms, they were more likely to show negative parenting behaviours in response to their ADHD child's misbehavior. These findings are consistent with evidence that fathers have a more distorted and negative view of their child's symptoms than mothers, and that they are more likely to attribute ADHD symptoms to internal causes that are controllable and changeable by the child (Chen, Seipp \& Johnston, 2008). Thus, similarity-fit/misfit models might look different in mothers and fathers, warranting an investigation of parental gender. Therefore, another objective of this study is to examine maternal and paternal ADHD separately to determine whether the models look different depending on parental gender.

\section{The current study}

The objective of this study was to investigate the extent to which teacher-reported adolescent externalizing behaviour, self-reported and parent-reported adolescent inattention and hyperactivity/impulsivity, and maternal and paternal self-reports of inattention and hyperactivity/impulsivity predict adolescent reported quantity and intensity of conflict with their parents. In accordance with findings from previous literature, and the similarity-fit and similarity-misfit models the following predictions and hypotheses were made: 
1. As was found in previous studies on parent-adolescent conflict (Barkley et al., 1991; 1992; Fletcher et al., 1996; Edwards et al., 2001), adolescent externalizing behaviour, as reported by teachers, would be associated with higher levels of adolescent-reported quantity and intensity of conflict with parents. As was found in previous studies on parent-adolescent conflict (Barkley et al., 1991; 1992; Fletcher et al., 1996; Edwards et al., 2001; Markel \& Wiener, 2014) self- and parent-reported adolescent ADHD symptoms (inattention and hyperactivityimpulsivity) would be associated with higher levels of adolescent-reported quantity and intensity of conflict with parents.

2. As was found in previous studies on parenting stress (Theule et al., 2011; Wiener, Biondic \& Grimbos, submitted) and studies on parent discipline and monitoring (Johnston et al., 2012; Chen \& Johnston, 2007), maternal inattention would predict higher levels of adolescent-reported conflict quantity and intensity over and above adolescent ADHD symptoms. Maternal hyperactivity-impulsivity and paternal ADHD symptoms would not predict higher levels of conflict over and above adolescent symptoms.

3. If the similarity-fit model were supported, parental ADHD symptoms would moderate the effect of adolescent ADHD symptoms on parent-adolescent quantity and intensity of conflict; conflict between parents and adolescents would be reduced when both have high levels of ADHD symptoms.

4. If the similarity-misfit model were supported, parental ADHD symptoms would moderate the effect of adolescent ADHD symptoms on parent-adolescent quantity 
and intensity of conflict; conflict between adolescents and parents would be increased when both have high levels of ADHD symptoms.

\section{Method}

\section{Participants}

The sample comprised 15613 to 18-year old adolescents (93 with ADHD, 63 without ADHD) and their parents from a large urban centre in Canada. We recruited the participants with ADHD through flyers sent to physicians and children's mental health centers, and by posting on websites of ADHD support organizations. We also contacted individuals who participated in previous studies. Typically developing adolescents in the comparison sample were recruited through advertisements placed in the community. All adolescent participants had average intellectual ability (IQ $\geq 85$ ).

Adolescents with ADHD were diagnosed with ADHD by a physician or psychologist at least one year prior to participating in the current study. Ongoing ADHD symptoms were confirmed using the DSM-IV scales of the Conners-3 (Conners, 2008). Participants were deemed to have ADHD when at least one rater (i.e., parent or teacher) reported that the adolescents' inattentive or hyperactive/impulsive symptoms were within the clinical range $(\mathrm{T} \geq 70)$ on the Conners-3, and the second rater (i.e., parent or teacher) indicated that the adolescents' inattentive or hyperactive/impulsive symptoms were within the borderline or clinical range $(T \geq 65)$. When teacher ratings were not available $(n=20)$, parent ratings were required to be within the clinical range and the adolescents' self-report in the borderline or clinical range. For participants in the comparison group, parent and teacher scores on the Conners-3 needed to fall within the average range $(\mathrm{T}<$ 65). If teacher ratings were not available $(n=11)$, adolescent self-report scores were 
required to be in the average range. Participants were excluded from the sample if they were diagnosed or suspected of having any of the following disorders: Autism Spectrum Disorders, Bipolar Disorder and Tourette's Disorder. Due to high comorbidity rates, we included participants with co-occurring learning disabilities, conduct disorder, oppositional defiant disorder, anxiety or depression.

Table 1 shows demographic and clinical differences between adolescents with and without ADHD. There was a trend towards a larger proportion of males in the ADHD group compared to the comparison group. ADHD adolescents were more likely than comparison adolescents to have received a comorbid diagnosis. In addition, ADHD adolescents demonstrated lower IQs, as measured by the Wechsler Abbreviated Scale of Intelligence (WASI; Wechsler, 1999), and their mothers were less educated than mothers of comparison adolescents. Finally, adolescent externalizing behaviour and maternal inattention were higher in adolescents with ADHD, compared to typically developing adolescents. There were no differences between ADHD and comparison adolescents with regards to age (mean age $=15.25$ years $)$, parental marital status $(72 \%$ of the total sample were married or common-law), father's education, number of people living in their household and siblings with ADHD. Concerning parental ADHD symptoms, maternal hyperactivity and paternal inattention and hyperactivity did not differ between the two adolescent subgroups.

In terms of parental participation in the current study, 65\% $(n=102)$ of the 156 adolescent participants had parental ADHD symptom ratings provided from both parents, $29 \%(n=45)$ had only mother ratings, and 7\% $(n=11)$ had only father ratings. 


\section{Measures}

The Conners Adult ADHD Self-Report Rating Scale- Short Version (CAARS$\mathrm{S}: \mathrm{SV}$; Conners, Erhardt, Sparrow, 1999) is a 30-item self-report measure that screens for inattention, hyperactivity and impulsivity in adults. The instrument has three subscales: DSM-IV inattentive symptoms, DSM-IV hyperactive/impulsive symptoms, DSM-IV Total ADHD symptoms, and ADHD index. Each item is rated on a 4-point Likert scale, ranging from 0 (Not at all true/Never) to 3 (Very Much/Very Frequently). Good psychometric properties have been reported; for example, the CAARS-S:SV produces an overall correct classification rate of $85 \%$ for adults with ADHD and strongly correlates with other adult clinical measures (Erhardt, Epstein, Conners, Parker, \& Sitarenios, 1999). In addition, internal consistency of subscales were reported to be .80 or higher for men and women (Conners et al., 1999).

The Conners-3 rating scales (Conners, 2008; Parent, Teacher, and Self-Report long forms) were used to measure ADHD and externalizing symptomology and behaviours in adolescents. Behaviors are rated on a 4-point scale ranging from 0 (Not at all/Seldom, Never) to 3 (Very Much True/ Very Often, Very Frequent). The two DSM-IV ADHD subscales (inattention and hyperactivity/impulsivity) and the oppositional defiant disorder (ODD), conduct disorder (CD) and aggression subscales demonstrate high internal consistency; for example, cronbach alphas for adolescents range from .84 to .93 (parent ratings) and .70 to .95 (teacher ratings). Cronbach alphas for the self-report DSMIV ADHD subscales range from .83 to .89. In terms of reliability, the mean test-retest correlation for the Conners-3 is .83, averaged across scales and rater types. The inter-rater reliability coefficient was estimated at .78, averaged across parent and teacher raters 
(Sparrow, 2010). Finally, the Conners -3 has strong convergent, discriminant and construct validity (Conners, 2008).

The Issues Checklist Abridged (IC; Prinz, Foster, Kent \& O’Leary, 1979) contains a list of 44 issues/conflicts typically experienced between parents and adolescents. Notably, one item about computer and internet use ("Have you discussed internet/computer use?") was added to this list as an updated (i.e., current) conflict and so the measure contained 45 items in total (Markel \& Wiener, 2014). Participants were asked to circle yes or no for issues they have or have not discussed with their parents during the last 4 weeks. Example items/issues include "Have you discussed smoking tobacco?" and "Have you discussed messing up the house?" For each issue marked yes, the participant uses a 5-point Likert scale to indicate how angry they were during the discussion, ranging from 1 (calm), 2 (a little angry), 3 and 4 (angry) and 5 (very angry). Participant adolescents in the current study completed one measure for both parents. The IC produces two composite scores. The first is the frequency of conflicts, which is the number of conflicts or issues endorsed over the past 4 weeks. The second composite is an intensity score, assessing how angry the adolescent felt during the conflict discussions. This instrument has demonstrated good reliability (Edwards et al., 2001) and has successfully discriminated between distressed and non-distressed families (Robin \& Foster, 1989).

\section{Procedure}

The study was approved by the university's Research Ethics Board. Parental and adolescent consent was obtained and parents (primarily mothers) completed the Conners3 parent rating scale (Conners, 2008). Parents of adolescents who met inclusion criteria 
based on the Conners-3 parent rating scale were then asked to complete a number of questionnaires for other studies online. Parents were also asked to give the Conners-3 teacher rating scale to a teacher whom the adolescents and parents believed could accurately comment on the adolescent's behaviours. Raters of the Conners-3 were asked to consider the adolescents' behaviours when they were not on medication. Adolescents and parents then came to the laboratory for a testing session. At this session, parents and adolescents completed a battery of questionnaires (including a demographic questionnaire and measures for other studies) and adolescents underwent cognitive testing with a trained graduate student in clinical psychology.

\section{Data Analysis}

Prior to performing analyses, data was checked for outliers by examining descriptive statistics and creating boxplots of the variables of interest. There were no outliers evident. Bivariate correlations were conducted in order to examine the intercorrelations among the key variables of interest. This was done for mother and fathers separately. To test for similarity fit/misfit, hierachical multiple regression analysis was performed separately for mothers and fathers. Hierarchical regression examined the independent contribution of adolescent and parental ADHD symptoms and their interaction on the dependent variables: adolescent-parent issues/conflict (frequency and intensity). In each regression model, youth externalizing problems was entered into Step 1 as a control variable. A composite of externalizing problems was created by adding the T-scores for Conners-3 parent and teacher ratings of aggression, CD and ODD (correlations between these variables ranged from .68 to .90). In Step 2, adolescent ADHD status and parental ADHD symptoms were entered into the model. In Step 3, the 
adolescent ADHD status X parental ADHD interaction term was entered. Variables in interactions were centered in order to reduce multicollinearity with other variables (ref). Four combinations of interactions between adolescent and parental ADHD were examined across models, resulting in eight models for mothers and eight for fathers. Combinations were: adolescent inattention, based on self and parent report, by parental inattention (inattention models) and adolescent hyperactivity/impulsivity, based on self and parent report, by parental hyperactivity/impulsivity (hyperactivity models). For each model, components of the interaction were examined as main effects; for example, when the model included the interaction for adolescent inattention (self report) X maternal inattention, main effects were also examined for each of these two variables separately. Significant interactions were probed using a technique described by Aiken and West (1991) whereby conditional effects of the main predictor (adolescent ADHD) were plotted at low, medium and high levels of the moderating variable (parental ADHD).

\section{Results}

\section{Bivariate correlations}

Table 2 presents correlations among key variables. The quantity of adolescentparent conflicts was significantly associated with both adolescent inattention and hyperactivity, based on self report. Quantity of conflicts was not related to maternal or paternal ADHD symptoms. Intensity of conflict was significantly correlated with adolescents externalizing problems, as well as adolescent inattention and hyperactivity symptoms, across raters. Intensity of adolescent-parent conflicts was also significantly related to maternal inattention. 


\section{Adolescent and maternal ADHD symptoms as predictors of adolescent-parent conflict}

Table 3 shows hierarchical regression results with adolescent-parent conflict, including quantity and intensity of conflict, as the dependent variables. Regarding main effects, adolescent inattention (self report) was the only main effect found to predict quantity of conflict. For conflict intensity, adolescent externalizing behaviour was a significant predictor of conflict intensity between adolescents and mothers when parent ratings of adolescent ADHD symptoms were entered in models. Significant main effects were also observed for adolescent inattention and adolescent hyperactivity, based on self reports. Regarding maternal ADHD symptoms, maternal inattention significantly predicted conflict intensity in the parent reported inattention model.

Concerning interaction effects, when the inattention model included adolescent inattention based on parent report, a significant adolescent inattention $\mathrm{X}$ maternal inattention effect was found on quantity of conflict, $\beta=.23 ; t(95)=2.22 ; p=.03$. Concerning this particular model, in step 2, the effect of the independent variables predicted almost $7 \%$ of the variance in quantity of conflict, with the interaction effect predicting an additional 5\% of the variance in step 3: $R^{2}=.11, F(4,95)=2.91, p=.03$. Figure 1 displays the plotted interaction effect between adolescent and maternal inattention on quantity of conflicts. Mothers with higher inattention experienced the greatest amount of conflict with adolescents who also showed higher inattention levels, compared to when adolescents had lower inattention. Mothers with the lowest levels of inattention showed less conflict with more inattentive adolescents. This plot suggests a similarity-misfit process because conflict is highest when both mothers and their 
adolescents exhibit higher levels of inattention. No significant interaction effects were found in hyperactivity models or when conflict intensity was the dependent variable. Adolescent and paternal ADHD symptoms as predictors of adolescent-parent conflict

Table 4 displays hierarchical regression results for fathers and parent-adolescent conflict as the dependent variable. For fathers, adolescent externalizing behavior was no longer significantly related to conflict intensity when adolescent ADHD symptoms were entered into the models. Significant main effects were found for adolescent symptoms whereby adolescent inattention (based on parent and self reports) and adolescent hyperactivity (self report) predicted intensity of conflict. Adolescent hyperactivity based on parent report did not predict intensity of conflict.

Concerning interaction effects and quantity of conflict, adolescent inattention based on parent report emerged as a significant predictor of quantity of conflict and there was a significant interaction between adolescent (parent report) and paternal inattention on the quantity of conflicts, $\beta=-.26 ; t(74)=-2.34 ; p=.02$. Concerning this particular model, in step 2, the effect of the independent variables predicted $6 \%$ of the variance in quantity of conflict, with the interaction effect predicting an additional $7 \%$ of the variance in step 3: $R^{2}=.13, F(4,74)=2.50, p=.05$. Figure 2 displays the plotted interaction effect between adolescent and paternal inattention on quantity of conflicts. This plot demonstrates a general pattern whereby fathers with low and medium levels of inattention showed more conflict with inattentive adolescents, but an opposite pattern emerged where the most inattentive fathers showed the least amount of conflict with their highly inattentive adolescents, compared to their less inattentive adolescents. This pattern of results is demonstrative of a similarity-fit process in fathers and adolescents with 
inattentive problems specifically. There were no significant interactions effects on conflict intensity in fathers.

\section{Discussion}

The current study identified some important differences between mothers and fathers with respect to the effects of adolescent externalizing behavior and adolescent and parental ADHD symptoms on the quantity and intensity of adolescent-parent conflict. For mothers, we found that teacher-rated adolescent externalizing problems predicted intensity of conflict when parent ratings of adolescent ADHD were also included in the models (adolescent externalizing was marginally predictive when self reports of adolescent ADHD were used). For fathers, teacher-rated adolescent externalizing behavior predicted intensity of adolescent-parent conflict, but this was no longer significant when adolescent ADHD symptoms (across reporters) were included in the model. In sum, concerning the effects of adolescent symptoms on conflict, adolescent externalizing behavior and adolescent ADHD symptoms were important predictors of conflict intensity for mothers, whereas adolescent ADHD symptoms were important for fathers. In addition, for mothers, symptoms of maternal inattention predicted conflict intensity; maternal hyperactivity did not. Neither paternal inattention nor hyperactivity impacted on conflict intensity for fathers.

Our study also demonstrated support for the similarity-misfit model in mothers. Mothers with medium and high levels of inattention showed more conflict with their adolescents who also had higher levels of inattention; in fact, mothers with the highest levels of inattention showed the greatest amount of conflict with adolescents who also had the highest levels of inattention (i.e., exacerbative effect). Conversely, there was 
evidence supporting the similarity-fit model in fathers with inattention and quantity of adolescent-parent conflict. The greatest number of conflicts occurred between fathers with the lowest levels of inattention and adolescents with the most elevated inattentive symptoms. As fathers showed more elevated symptoms themselves, there was a shift in conflict quantity whereby fewer conflicts were experienced with adolescents with higher levels of inattentive symptoms compared to those with lower levels.

The robust impact of adolescent externalizing behavior on adolescent-mother conflict is indeed consistent with many other studies showing that adolescent externalizing behaviour predicts rates and degree of conflict between mothers and adolescents with ADHD (Barkley et al., 1991; 1992; Fletcher et al., 1996; Edwards et al., 2001). Many of these studies found that externalizing problems actually accounted for most of the variance in conflict; however, we found support that adolescent ADHD symptoms were also predictive of conflict intensity with mothers. Only one study (Edwards et al., 2001) specifically examined adolescent-father conflict in relation to the relative importance of adolescent ADHD and externalizing. This study demonstrated that ADHD adolescents with comorbid ODD showed higher rates and more intense conflict, compared to community controls. In our study, adolescent ADHD symptoms (but not externalizing behaviour) was an important predictor of conflict intensity in fathers, consistent with other research showing parenting difficulties in fathers of children with ADHD (Harvey et al., 2003).

We also found that maternal inattention predicted conflict intensity above and beyond adolescent symptoms. This was not replicated in fathers, nor did we find support that hyperactivity symptoms (maternal or paternal) predicted conflict intensity. These 
results, consistent with other research on maternal inattention and parenting deficits (Chen \& Johnston, 2007; Murray \& Johnston, 2006), may best be explained by the fact that mothers play primary and more active roles in children's day-to-day lives, compared to fathers. As such, mothers are typically more involved in activities such as getting their children out of bed and off to school in the morning, supervising homework, arranging pick-ups and play dates, making lunches and dinners, and so forth. These various responsibilities may be most difficult to execute when mothers struggle with inattention and related executive functioning deficits, leading to frustration and more intense conflict with their adolescents. The possible frustration experienced by mothers may be reflected in the finding that intensity (i.e., heatedness) of conflict was impacted by maternal inattention, and not the sheer number of conflicts.

Adolescent problems, including externalizing and ADHD symptomatology, also predicted conflict between adolescents and mothers, indicating that the intensity of adolescent-mother conflict is driven by both adolescent and maternal symptomatology. This finding, along our results supporting the similarity-misfit model in mothers, can also be interpreted in the context of parenting and gender roles. Given the primarily role of mothers in families, they are typically more aware of what happens in the daily lives of their children and adolescents (Parke, 2000; Bianchi \& Raley, 2005). Mothers also tend to invest more in family relationships and are generally more attuned to and concerned about interpersonal behaviours and relationships (Nolen-Hoeksema, 2012). As such, mothers may have a heightened awareness about how they impact their children and how their children impact them. Empirical evidence also suggests that females with ADHD are more likely to experience internalizing problems and have self esteem issues 
(Biederman et al., 2010; Rucklidge \& Kaplan, 1997). Taken together, these factors may explain our results in mothers, including the importance of mothers' own inattentive symptoms and their children's symptoms (e.g., externalizing and ADHD symptoms) on the intensity of conflict. Johnston et al. (2012) suggested that executive functioning deficits in adults with ADHD impact on parenting by influencing both parental cognitions and behaviours. Regarding the impact on cognitions, involved mothers' inattentive symptoms, especially in the face of adolescent impairment, may lead to mothers feeling overwhelmed and distressed regarding their childcare responsibilities. Mothers may also feel guilty and to blame for their children's difficulties or they may believe they are ineffective parents. Feelings of frustration, guilt and overburden may impact the way mothers behave with her adolescent; for example, engaging in more heated conflicts, yelling, and being generally less patient with their children. This process is reflected in our results suggesting the presence of the similarity-misfit process in mothers whereby adolescents and mothers engage in the most conflict when both maternal and adolescent inattentive symptoms are highest. Notably, these results are also consistent with findings from a recent study by Babinski and colleagues (2012) where mothers with ADHD reported the highest levels of conflict with adolescents with ADHD, compared to mothers who did not have ADHD. That we did not find evidence for a similarity fit phenomenon in mothers may be a result of mothers feeling extremely stressed, guilty and overwhelmed, especially during adolescence and with an adolescent who struggles with multiple impairments. These feelings of distress may actually overpower any feelings of sympathy or tolerance mothers may have towards their adolescents. 
Fathers, on the other hand, may be more removed from the stressful daily lives of their adolescent children, possibly explaining why we found support for the similarity-fit model in fathers. Fathers may be freed from some of the burdens of stress and responsibility and can carry a more empathic perspective towards their children. Research has also shown that fathers are more likely to engage in recreational and leisure activities with their child (Hosley \& Montemajor, 1997), thus potentially altering the nature of the relationship towards a more playful and less discordant one. Furthermore, fathers may not be as aware of their children's various behaviours if they are involved less, and perhaps they may even tolerate certain behaviours more than mothers (e.g., aggression). In fact, this may help explain the findings that adolescent externalizing behavior was a more robust predictor of conflict intensity in mothers, but not so in fathers. Fathers may also be less insightful and thus less critical of their own cognitive impairments (and the impact on their adolescents), compared to mothers.

\section{Limitations}

The results of the current study should be interpreted in light of several limitations. For one, we employed a cross-sectional design and so causal relationships cannot be concluded. A longitudinal design would better speak to causal processes and future research should consider this type of methodology. Relatedly, future research may consider investigating the intricacies of the similarity-fit/misfit processes in fathers and mothers; for example, the role of same parent and child gender, as well causal processes related to stress and conflict. Kendall and colleagues (2005) examined a sample of families with children and youth with ADHD and found that maternal distress mediated the link between child behaviorial problems and family conflict (Kendall, Leo, Perrin \& 
Hatton, 2005). This process should be further explored. In addition, adolescents provided ratings for conflict regarding both mothers and fathers at the same time. This was a limitation not only because of the single rater perspective but also because ratings were not provided for mothers and fathers separately. Finally, approximately $22 \%(n=34)$ of the sample had missing data on teacher ratings of adolescent behaviours on Conners-3. As a result, regression models, which included teacher-rated externalizing behaviours as covariate, had reduced statistical power, particularly for fathers ( $n=95$ for maternal regression models and $n=74$ for paternal regression models). However, using teacherrated externalizing as a covariate in the regression models enhanced our analyses because of the inclusion of multiple raters' perspectives (e.g., parents, adolescents and teachers). Conclusions, future directions and clinical implications

This study is the first to investigate the similarity-fit/misfit process in adolescent families with ADHD, and one of few studies to look at conflict in parents of adolescents with ADHD. Our results demonstrated evidence that the similarity-misfit process may be active in ADHD mothers whereas similarity-fit may be more evident in ADHD fathers, specifically in relation to the number of adolescent-parent conflicts. Results concerning mothers suggest that mothers' own inattentive symptoms and the level of externalizing and ADHD symptomatology in adolescents independently contribute to greater intensity of conflict. We suggest that mothers may be so overwhelmed with the stress and burden of raising an adolescent with ADHD that there is little opportunity to experience empathy and tolerance towards their adolescents; fathers may have a different perspective based on their parental role. 
Future research should build on the current study's findings, looking specifically at differential parental roles and how that impacts perceptions towards children and adolescents. Results also have implications for involving parents in treatments for ADHD in teenagers, and in teaching coping strategies for stress and conflict resolution in mothers particularly in relation to her own executive functioning deficits and possible concerns (i.e., self-blame) about the impact of her symptoms on her child. Involvement of fathers in treatment may include encouragement and teaching ways to assist with some of the childcare responsibilities in order to alleviate stress and perhaps even increase time spent on recreational activities with adolescents. This may serve to reduce serious conflicts between mothers and their adolescents and within the family at large. In addition to reducing stressors for primary caregivers in families, our research results also point to the potential benefit of enhancing parents' understanding and tolerance for adolescent behaviours. One way to accomplish this may be to emphasize similarities between adolescent and parental symptomatology to increase empathy. 


\section{References}

Aiken, L. S., \& West, S. G. (1991). Multiple regression: Testing and interpreting interactions. Newbury Park, CA: Sage.

Babinki, D. E., Pelham, W. E., Molina, B. S. G., Gnagy, E. M., Waschbusch, D. A., Wymbs, B. T.,...Kuriyan, A. B. (2014). Maternal ADHD, parenting, and psychopathology among mothers of adolescents with ADHD. Journal of Attention Disorders. Doi: $10.1177 / 1087054712461688$

Barkley, R. A., Anastopoulos, A. D., Guevremont, D. C., \& Fletcher, K. E. (1992). Adolescents with attention deficit hyperactivity disorder: Mother adolescent interactions, family beliefs and conflicts, and maternal psychopathology. Journal of Abnormal Child Psychology, 20, 263-288. doi:10.1007/BF00916692

Barkley, R. A., Fischer, M., Edelbrock, C. S., \& Smallish, L. (1991). The adolescent outcome of hyperactive children diagnosed by research criteria, I: Mother-child interactions, family conflicts, and maternal psychopathology. Journal of Child Psychology and Psychiatry, 32, 233-255.

Bianchi, S. M., \& Raley, S. B. (2005). Time allocation in families. In S. M. Bianchi, L. M. Casper, \& R. B. King (Eds.), Work, family, health, and well-being ada).(pp. 21- 
42). New Jersey: Erlbaum.

Biederman, J., Faraone, S. V., \& Monuteaux, M. C. (2002). Impact of exposure to parental attention-deficit hyperactivity disorder on clinical features and dysfunction in the offspring. Psychological Medicine: A Journal of Research in Psychiatry and the Allied Sciences, 32, 817-827.

Biederman, J., Petty, C. R., Monuteaux, M. C., Fried, R., Byrne, D., Mirto, T.,...Faraone, S. V. (2010). Adult psychiatric outcomes of girls with attention deficit hyperactivity disorder: 11-year follow-up in a longitudinal case-control study. American Journal of Psychiatry, 167, 409-417

Chen, M., \& Johnston, C. (2007). Maternal inattention and impulsivity and parenting behaviors. Journal of Clinical Child and Adolescent Psychology, 36, 455-468.

Chen, M., Seipp, C., \& Johnston, C. (2008). Mothers' and fathers' attributions and beliefs in families of girls and boys with attention-deficit/hyperactivity disorder. Child Psychiatry and Human Development, 39, 85-99. doi:10.1007/s10578-007-0073-6

Chronis-Tuscano, A., Raggi, V. L., Clarke, T. L., Rooney, M. E., Diaz, Y., \& Pian, J. (2008). Associations between maternal attention-deficit/hyperactivity disorder symptoms and parenting. Journal of Abnormal Child Psychology, 36, 1237-1250. 
doi:10.1007/s10802-008-9246-4

Conners, C. K. (2008). Conners-3 (3rd edition). Toronto, Canada: Multi-Health Systems.

Conners, C. K., Erhardt, D., \& Sparrow, E. (1999). Conners' adult ADHD rating scales (CAARS) technical manual. Toronto, Canada: Multi-Health Systems.

Deault, L. C. (2010). A systematic review of parenting in relation to the development of comorbidities and functional impairments in children with attention-deficit/ hyperactivity disorder (ADHD). Child Psychiatry and Human Development, 41, 168-192. doi:10.1007/s10578-009-0159-4

Edwards, G., Barkley, R. A., Laneri, M., Fletcher, K., \& Metevia, L. (2001). Parentadolescent conflict in teenagers with ADHD and ODD. Journal of Abnormal Child Psychology, 29, 557-572. doi:10.1023/A:1012285326937

Erhardt, D., Epstein, J. N., Conners, C. K., Parker, J. D. A., \& Sitarenios, G. (1999). Selfratings of ADHD symptoms in adults II. Reliability, validity, and diagnostic sensitivity. Journal of Attention Disorders, 3, 153-158.

Fischer, M. (1990). Parenting stress and the child with attention-deficit/hyperactivity disorder. Journal of Clinical Child and Adolescent Psychology, 19, 337-346. 
Fletcher, K. E., Fischer, M., Barkley, R. A., \& Smallish, L. (1996). A sequential analysis of the mother-adolescent interactions of ADHD, ADHD/ODD, and normal teenagers during neutral and conflict discussions. Journal of Abnormal Child Psychology, 24, 271-297. doi:10.1007/BF01441632

Griggs, M. S., \& Mikami, A. Y. (2011). The role of maternal and child ADHD symptoms in shaping interpersonal relationships. Journal of Abnormal Child Psychology, 39, 437-449.

Harvey, E., Danforth, J. S., Eberhardt, McKee, T., Ulaszek, W. R., \& Friedman, J. L. (2003). Parenting of children with attention-Deficit/Hyperactivity disorder (ADHD): The role of parental ADHD symptomatology. Journal of Attention Disorders, 7, 31-42. doi:10.1177/108705470300700104

Hosley, C. A., \& Montemayor, R. (1997). Fathers and adolescents. In M. E. Lamb (Ed.), The role of the father in child development (pp. 163-178). New York: Wiley.

Ingoldsby, E. M., Shaw, D. S., Winslow, E., Schonberg, M., Gilliom, M., Criss, M. M. (2006). Neighborhood disadvantage, parent-chilld confliict, neighborhood peer relationships, and early antisocial behavior problem trajectories. Journal of Abnormal Child Psychology. 34, 303-319. 
Johnston, C., Mash, E. J., Miller, N., \& Ninowski, J. E. (2012). Parenting in adults with attention-deficit/hyperactivity disorder (ADHD). Clinical Psychology Review, 32, 215-228. doi: 10.1016/j.cpr.2012.01.007

Kendall, J., Leo, M. C., Perrin, N., Hatton, D. (2005). Modeling ADHD child and family relationships. Western Journal of Nursing Research, 27, 500-518.

Markel, C., \& Wiener, J. (2014). Attribution processes in parent-adolescent conflict in families of adolescents with and without ADHD. Canadian Journal of Behavioural Science/Revue Canadienne Des Sciences Du Comportement, 46, 40-48. doi: 10.1037/a0029854

Mokrova, I., O’Brien, M., Calkins, S. \& Keane, S. (2010). Parental ADHD symptomology and ineffective parenting: The connecting link of home chaos. Parenting, 10, 119- 135. doi:10.1080/15295190903212844

Murray, C., \& Johnston, C. (2006). Parenting in mothers with and without AttentionDeficit/Hyperactivity Disorder. Journal of Abnormal Psychology, 115, 52-61.

Nolen-Hoeksema, S. (2012). Emotion Regulation and Psychopathology: The Role of Gender. Annual Review of Clinical Psychology, 8, 161-187. doi: 10.1146/annurevclinpsy-032511-143109 
Parke, R. D. (2000). Father involvement: A developmental psychological perspective. Marriage and Family Review, 29, 43-58. doi:10.1300/J002v29n02_04

Patterson, G. R., Reid, J. B., \& Dishion, T. J. (1992). Antisocial boys. Eugene, OR: Castalia.

Prinz, R. J., Foster, S., Kent, R. N., \& O'Leary, K. D. (1979). Multivariate assessment of conflict in distressed and nondistressed mother-adolescent dyads. Journal of Applied Behavior Analysis, 12, 691-700. doi:10.1901/jaba.1979.12-691

Psychogiou, L., Daley, D. M., Thompson, M. J., \& Sonuga-Barke, E. J. S. (2007). Mothers' expressed emotion toward their school-aged sons: Associations with child and maternal symptoms of psychopathology. European Child \& Adolescent Psychiatry, 16, 458-464. doi:10.1007/s00787-007-0619-y

Psychogiou, L., Daley, D., Thompson, M. J., \& Sonuga-Barke, E. J. S. (2008). Parenting empathy: Associations with dimensions of parent and child psychopathology. British Journal of Developmental Psychology, 26, 221-232.

Robin, A. L., \& Foster, S. L. (1989). Negotiating parent-adolescent conflict: A behavioral-family systems approach. New York, NY: Guilford Press. 
Rohde, L. A., Biederman, J, Busnello, E. A., Zimmerman, H., Schmitz, M., Martins, S., \& Tramontina, S. (1999). ADHD in a school sample of Brazilian adolescents: A study of prevalence, comorbid conditions, and impairment. Journal of the American Academcy of Child and Adolescent Psychiatry, 38, 716-72.

Rucklidge, J. J., Kaplan, B. J. (1997). Psychological functioning in women identified in adulthood with Attention-Deficit/Hyperactivity Disorder. Journal of Attention Disorders, 2, 167-176.

Steinberg, L., \& Morris , A. S. ( 2001 ). Adolescent development. In S. T. Fiske, D. L. Schacter , \& C. Zahn - Waxler (Eds.), Annual review of psychology (pp. 83-110 ). Palo Alto, CA: Annual Reviews.

Theule, J., Wiener, J., Jenkins, J. \& Tannock, R. (2013). Parenting stress in families of children with ADHD: A meta-analysis. Journal of Emotional and Behavioral Disorders, 21, 3-17.

Theule, J., Wiener, J., Rogers, M. A. \& Marton, I. (2011). Predicting parenting stress in families of children with ADHD: Parent and contextual factors. Journal of Child and Family Studies, 20, 640-647. doi:10.1007/s10826-010-9439-7 
Van Doorn, M. D., Branje, S. J. T., \& Meeus, W. H. J. (2008). Conflict resolution in parent-adolescent relationships and adolescent delinquency. The Journal of Early Adolescence, 28, 503-527.

Wechsler, D. (1999). Manual for the Wechsler Abbreviated Scale of Intelligence (WASI). San Antonio, TX: Psychological Corporation.

Wiener, J., Biondic, D., \& Grimbos, T. (2014). Parenting stress of parents of adolescents with Attention-Deficit Hyperactivity Disorder. Manuscript submitted for publication.

Williamson, D. K., (2013). How parent and child attention-deficit/hyperactivity disorder symptoms predict parenting behaviour in mothers and fathers: Self report and observational measures (Unpublished master's thesis). The University of British Columbia, Vancouver. 


\section{Tables}

Table 1

Comparison Between ADHD and Comparison Adolescents in Demographic and Clinical Factors

\begin{tabular}{|c|c|c|c|}
\hline Demographic variable: & $\begin{array}{l}\text { ADHD } \\
(n=93)\end{array}$ & $\begin{array}{c}\text { Comparison } \\
(n=63)\end{array}$ & F-statistic \\
\hline Adolescent age & $15.19(1.68)$ & $15.33(1.65)$ & $.26, \mathrm{~ns}$ \\
\hline Adolescent IQ & $103.10(12.78)$ & $110.10(9.80)$ & $13.01^{* *}$ \\
\hline Mother's education & $8.19(1.45)$ & $9.06(1.33)$ & $11.05^{* *}$ \\
\hline Father's education & $8.07(1.99)$ & $8.57(1.60)$ & 2.05 \\
\hline \multirow[t]{2}{*}{ Number of people in household } & $3.95(1.12)$ & $4.14(1.23)$ & 1.07 \\
\hline & ADHD & Comparison & Chi square \\
\hline Adolescent gender & & & $4.06+$ \\
\hline Male & $58(62)$ & $29(46)$ & \\
\hline Female & $35(38)$ & $34(54)$ & \\
\hline Parental marital status & & & 1.98 \\
\hline Single & $10(11)$ & $3(5)$ & \\
\hline Married or common-law & $65(70)$ & $48(76)$ & \\
\hline Separated or divorced & $17(19)$ & $11(18)$ & \\
\hline Widowed & $1(1)$ & $1(2)$ & \\
\hline Clinical variable: & ADHD & Comparison & F-statistic \\
\hline Adolescent externalizing (teacher) & $176.99(44.35)$ & $152.83(30.32)$ & $11.44^{* *}$ \\
\hline Maternal inattention & $54.14(15.15)$ & $44.64(11.94)$ & $15.27 * *$ \\
\hline Maternal hyperactivity & $45.10(10.34)$ & $42.43(7.45)$ & 2.67 \\
\hline Paternal inattention & $52.72(14.95)$ & $48.76(14.65)$ & 1.76 \\
\hline Paternal hyperactivity & $56.38(13.91)$ & $52.50(11.05)$ & 2.31 \\
\hline Adolescent-parent conflict - quantity & $16.84(7.17)$ & $19.49(10.14)$ & $2.86 \dagger$ \\
\hline \multirow[t]{2}{*}{ Adolescent-parent conflict-intensity } & $1.96(.70)$ & $1.72(.59)$ & $4.45^{*}$ \\
\hline & ADHD & Comparison & Chi square \\
\hline Comorbid diagnosis-any & $66(71)$ & $1(2)$ & $58.58^{* *}$ \\
\hline Learning disability diagnosis & $57(61)$ & $7(11)$ & $39.09 * *$ \\
\hline Anxiety or depression diagnosis & $14(15)$ & $1(2)$ & $7.84^{*}$ \\
\hline Conduct or oppositional diagnosis & $3(3)$ & $1(2)$ & .39 \\
\hline ADHD medication & $66(71)$ & $0(0)$ & $41.43 * *$ \\
\hline Sibling with ADHD diagnosis & $27(29)$ & $14(23)$ & .62 \\
\hline
\end{tabular}

Note. ${ }^{* *} \mathrm{p}<.001 ;{ }^{*} \mathrm{p}<.05$. F-statistic, means and standard deviations (SD in brackets) presented for continuous variables; chi square statistic, n's and percentages (\% in brackets) presented for categorical variables ( $n$ 's and percentages are within adolescent ADHD status subgroup). Parental education is measured on an 11-point scale: $1=$ no schooling, $5=$ completed secondary school, $6=$ some college, $7=$ completed college, $8=$ some university, $9=$ completed undergraduate degree, $10-11$ = postgraduate education. 
Table 2

Correlations among key variables

\begin{tabular}{|c|c|c|c|c|c|c|c|c|c|c|c|}
\hline Variable & 1. & 2. & 3. & 4. & 5. & 6. & 7. & 8. & 9. & 10. & 11. \\
\hline 1. Conflict (quantity) & - & $.23 * *$ & .10 & $.16 \dagger$ & $.21 * *$ & .12 & $.22^{*}$ & .06 & .04 & .01 & .05 \\
\hline 2. Conflict (intensity) & & - & $.28 * *$ & $.21^{*}$ & $.32 * *$ & $.20^{*}$ & $.35^{* *}$ & $.35^{* *}$ & .04 & .10 & .11 \\
\hline $\begin{array}{l}\text { 3. Adolescent externalizing } \\
\text { (teacher) }\end{array}$ & & & - & $.27^{* *}$ & $.26 * *$ & $.29 * *$ & $.31^{* *}$ & -.13 & -.04 & $.26^{*}$ & .12 \\
\hline 4. Adolescent inattention (parent) & & & & - & $.42 * *$ & $.77^{* *}$ & $.42^{* *}$ & $.29 * *$ & .12 & .11 & .12 \\
\hline 5. Adolescent inattention (self) & & & & & - & $.44^{* *}$ & $.72^{* *}$ & $.30 * *$ & .03 & .15 & $.19 *$ \\
\hline $\begin{array}{l}\text { 6. Adolescent hyperactivity } \\
\text { (parent) }\end{array}$ & & & & & & - & $.46^{* *}$ & $.30 * *$ & $.18^{*}$ & .11 & $.17+$ \\
\hline 7. Adolescent hyperactivity (self) & & & & & & & - & $.34^{* *}$ & .12 & .13 & .13 \\
\hline 8. Maternal inattention & & & & & & & & - & $.46^{* *}$ & .04 & $.20 \dagger$ \\
\hline 9. Maternal hyperactivity & & & & & & & & & - & .08 & .14 \\
\hline 10. Paternal inattention & & & & & & & & & & - & $.77^{* *}$ \\
\hline 11. Paternal hyperactivity & & & & & & & & & & & - \\
\hline
\end{tabular}

Note. ${ }^{* *} p<.01,{ }^{*} p<.05$ 
Table 3. Hierarchical multiple regression results for parent-adolescent conflict (mothers)

\begin{tabular}{|c|c|c|c|c|c|c|c|c|c|c|c|c|}
\hline & \multicolumn{6}{|c|}{ Conflict - quantity } & \multicolumn{6}{|c|}{ Conflict - intensity } \\
\hline & $\mathbf{R}^{2}$ & $\Delta R^{2}$ & B & SE(B) & B & $p$ value & $\mathbf{R}^{2}$ & $\Delta \mathbf{R}^{2}$ & B & SE(B) & $\beta$ & $p$ value \\
\hline (Step 1): Adolescent externalizing & .01 & .01 & .02 & .02 & .09 & .38 & .07 & $.07^{*}$ & .00 & .00 & .25 & $.01 *$ \\
\hline (Step 2): Adolescent externalizing & .07 & $.06+$ & .01 & .02 & .05 & .65 & .14 & $.07^{*}$ & .00 & .00 & .25 & $.02 *$ \\
\hline Adolescent inattention (parent) & & & .08 & .06 & .16 & .16 & & & .00 & .00 & .07 & .50 \\
\hline Maternal inattention & & & .09 & .07 & .15 & .18 & & & .01 & .01 & .24 & $.02 *$ \\
\hline (Step 3): Adolescent externalizing & .11 & $.05^{*}$ & .02 & .02 & .07 & .50 & .14 & .00 & .01 & .00 & .25 & $.02 *$ \\
\hline Adolescent inattention (parent) & & & .11 & .06 & .21 & $.06+$ & & & .00 & .00 & .09 & .45 \\
\hline Maternal inattention & & & .08 & .07 & .13 & .23 & & & .01 & .01 & .24 & $.02 *$ \\
\hline $\begin{array}{l}\text { Adolescent inattention } \mathrm{X} \text { maternal } \\
\text { inattention }\end{array}$ & & & .01 & .00 & .23 & $.03^{*}$ & & & .00 & .00 & .04 & .69 \\
\hline (Step 1): Adolescent externalizing & .01 & .01 & .02 & .02 & .09 & .38 & .07 & $.07^{*}$ & .00 & .00 & .25 & .01 \\
\hline (Step 2): Adolescent externalizing & .10 & $.09 *$ & .01 & .02 & .04 & .73 & .23 & $.17^{* *}$ & .00 & .00 & .18 & $.07+$ \\
\hline Adolescent inattention (self) & & & .17 & .07 & .25 & $.03^{*}$ & & & .02 & .01 & .34 & $.00 * *$ \\
\hline Maternal inattention & & & .07 & .07 & .11 & .30 & & & .01 & .01 & .16 & .10 \\
\hline (Step 3): Adolescent externalizing & .12 & .02 & .01 & .02 & .04 & .69 & .23 & .00 & .00 & .00 & .18 & $.07+$ \\
\hline Adolescent inattention (self) & & & .17 & .07 & .25 & $.03^{*}$ & & & .02 & .01 & .34 & $.00 * *$ \\
\hline Maternal inattention & & & .03 & .07 & .05 & .67 & & & .02 & .01 & .17 & $.09+$ \\
\hline $\begin{array}{l}\text { Adolescent inattention } \mathrm{X} \text { maternal } \\
\text { inattention }\end{array}$ & & & .01 & .01 & .16 & .13 & & & .00 & .00 & -.02 & .74 \\
\hline (Step 1): Adolescent externalizing & .01 & .01 & .02 & .02 & .09 & .38 & .07 & $.07^{*}$ & .00 & .00 & .25 & .01 \\
\hline (Step 2): Adolescent externalizing & .04 & .03 & .01 & .02 & .04 & .74 & .09 & .03 & .00 & .00 & .24 & $.03^{*}$ \\
\hline Adolescent hyperactivity (parent) & & & .09 & .06 & .17 & .13 & & & .00 & .00 & .10 & .36 \\
\hline Maternal hyperactivity & & & .03 & .10 & .04 & .74 & & & .01 & .01 & .12 & .27 \\
\hline (Step 3): Adolescent externalizing & .04 & .01 & .01 & .02 & .04 & .72 & .11 & .03 & .00 & .00 & .24 & $.03^{*}$ \\
\hline
\end{tabular}




\begin{tabular}{|c|c|c|c|c|c|c|c|c|c|c|c|c|}
\hline Adolescent hyperactivity (parent) & & & .09 & .06 & .17 & .14 & & & .00 & .00 & .10 & .37 \\
\hline Maternal hyperactivity & & & .02 & .10 & .02 & .87 & & & .01 & .01 & .08 & .47 \\
\hline $\begin{array}{l}\text { Adolescent hyperactivity } \mathrm{X} \\
\text { maternal hyperactivity }\end{array}$ & & & .00 & .01 & .07 & .49 & & & .00 & .00 & .17 & .10 \\
\hline (Step 1): Adolescent externalizing & .01 & .01 & .02 & .02 & .09 & .38 & .07 & $.07^{*}$ & .00 & .00 & .25 & .01 \\
\hline (Step 2): Adolescent externalizing & .04 & .04 & .01 & .02 & .06 & .58 & .19 & $.13 * *$ & .00 & .00 & .19 & $.05 *$ \\
\hline Adolescent hyperactivity (self) & & & .13 & .08 & .18 & .10 & & & .02 & .01 & .34 & $.00 * *$ \\
\hline Maternal hyperactivity & & & .05 & .10 & .05 & .65 & & & .01 & .01 & .09 & .37 \\
\hline (Step 3): Adolescent externalizing & .04 & .00 & .01 & .02 & .06 & .59 & .19 & .00 & .00 & .00 & .19 & $.06+$ \\
\hline Adolescent hyperactivity (self) & & & .13 & .08 & .18 & .10 & & & .02 & .01 & .34 & $.00 * *$ \\
\hline Maternal hyperactivity & & & .05 & .10 & .05 & .63 & & & .01 & .01 & .09 & .38 \\
\hline $\begin{array}{l}\text { Adolescent hyperactivity } X \\
\text { maternal hyperactivity }\end{array}$ & & & .00 & .01 & -.02 & .89 & & & .00 & .00 & .00 & .99 \\
\hline
\end{tabular}


Table 4. Hierarchical multiple regression results for parent-adolescent conflict (fathers)

\begin{tabular}{|c|c|c|c|c|c|c|c|c|c|c|c|c|}
\hline & \multicolumn{6}{|c|}{ Conflict - quantity } & \multicolumn{6}{|c|}{ Conflict - intensity } \\
\hline & $\mathbf{R}^{2}$ & $\Delta R^{2}$ & B & SE(B) & $\beta$ & $p$ value & $\mathrm{R}^{2}$ & $\Delta \mathbf{R}^{2}$ & B & SE(B) & $\beta$ & $p$ value \\
\hline (Step 1): Adolescent externalizing & .00 & .00 & .01 & .03 & .04 & .73 & .05 & $.05^{*}$ & .00 & .00 & .23 & $.05^{*}$ \\
\hline (Step 2): Adolescent externalizing & .06 & .06 & -.01 & .03 & -.03 & .79 & .11 & .06 & .00 & .00 & .15 & .21 \\
\hline Adolescent inattention (parent) & & & .13 & .06 & .25 & $.05^{*}$ & & & .01 & .00 & .25 & $.04^{*}$ \\
\hline Paternal inattention & & & -.01 & .07 & -.01 & .92 & & & .00 & .00 & -.01 & .91 \\
\hline (Step 3): Adolescent externalizing & .13 & $.07 *$ & -.01 & .03 & -.02 & .84 & .11 & .01 & .00 & .00 & .16 & .21 \\
\hline Adolescent inattention (parent) & & & .13 & .06 & .25 & $.04 *$ & & & .01 & .00 & .25 & $.04^{*}$ \\
\hline Paternal inattention & & & -.02 & .07 & -.04 & .75 & & & -.00 & .00 & -.02 & .87 \\
\hline $\begin{array}{l}\text { Adolescent inattention } \mathrm{X} \text { paternal } \\
\text { inattention }\end{array}$ & & & -.01 & .00 & -.26 & $.02 *$ & & & .00 & .00 & -.07 & .53 \\
\hline (Step 1): Adolescent externalizing & .00 & .00 & .01 & .03 & .04 & .73 & .05 & $.05^{*}$ & .00 & .00 & .23 & $.05^{*}$ \\
\hline (Step 2): Adolescent externalizing & .05 & .05 & .01 & .03 & .00 & .99 & .19 & $.13^{*}$ & .00 & .00 & .16 & .15 \\
\hline Adolescent inattention (self) & & & .16 & .08 & .22 & $.06+$ & & & .02 & .01 & .37 & $.00 * *$ \\
\hline Paternal inattention & & & -.01 & .07 & -.02 & .87 & & & -.00 & .00 & -.03 & .78 \\
\hline (Step 3): Adolescent externalizing & .09 & $.04 \dagger$ & .01 & .03 & .02 & .85 & .20 & .01 & .00 & .00 & .17 & .13 \\
\hline Adolescent inattention (self) & & & .15 & .08 & .21 & $.07+$ & & & .02 & .01 & .37 & $.00 * *$ \\
\hline Paternal inattention & & & -.07 & .07 & -.12 & .35 & & & -.00 & .01 & -.08 & .50 \\
\hline $\begin{array}{l}\text { Adolescent inattention } \mathrm{X} \text { paternal } \\
\text { inattention }\end{array}$ & & & -.10 & .01 & -.23 & $.08+$ & & & .00 & .00 & -.12 & .33 \\
\hline (Step 1): Adolescent externalizing & .00 & .00 & .01 & .03 & .04 & .73 & .05 & $.05^{*}$ & .00 & .00 & .23 & $.05^{*}$ \\
\hline (Step 2): Adolescent externalizing & .04 & .04 & -.01 & .03 & -.03 & .81 & .09 & .04 & .00 & .00 & .16 & .19 \\
\hline Adolescent hyperactivity (parent) & & & .10 & .06 & .20 & .11 & & & .01 & .00 & .19 & .12 \\
\hline Paternal hyperactivity & & & .04 & .08 & .06 & .63 & & & .00 & .01 & .06 & .64 \\
\hline (Step 3): Adolescent externalizing & .04 & .00 & -.01 & .03 & -.03 & .81 & .09 & .00 & .00 & .00 & .16 & .19 \\
\hline
\end{tabular}




\begin{tabular}{|c|c|c|c|c|c|c|c|c|c|c|c|c|}
\hline Adolescent hyperactivity (parent) & & & .10 & .06 & .20 & .11 & & & .01 & .00 & .19 & .12 \\
\hline Paternal hyperactivity & & & .04 & .08 & .05 & .67 & & & .00 & .01 & .06 & .62 \\
\hline $\begin{array}{l}\text { Adolescent hyperactivity } \mathrm{X} \\
\text { paternal hyperactivity }\end{array}$ & & & .00 & .00 & .01 & .95 & & & .00 & .00 & -.02 & .85 \\
\hline (Step 1): Adolescent externalizing & .00 & .00 & .01 & .03 & .04 & .73 & .05 & $.05^{*}$ & .00 & .00 & .23 & $.05^{*}$ \\
\hline (Step 2): Adolescent externalizing & .04 & .04 & -.01 & .03 & -.01 & .93 & .20 & $.15^{*}$ & .00 & .00 & .14 & .21 \\
\hline Adolescent hyperactivity (self) & & & .14 & .08 & .20 & .11 & & & .02 & .01 & .39 & $.00 * *$ \\
\hline Paternal hyperactivity & & & .04 & .08 & .06 & .61 & & & .00 & .01 & .03 & .78 \\
\hline (Step 3): Adolescent externalizing & .05 & .01 & .00 & .03 & -.01 & .94 & .21 & .01 & .00 & .00 & .14 & .21 \\
\hline Adolescent hyperactivity (self) & & & .13 & .09 & .19 & .13 & & & .02 & .01 & .38 & $.00 * *$ \\
\hline Paternal hyperactivity & & & .03 & .09 & .05 & .70 & & & .00 & .01 & .00 & .99 \\
\hline $\begin{array}{l}\text { Adolescent hyperactivity } \mathrm{X} \\
\text { paternal hyperactivity }\end{array}$ & & & -.00 & .01 & -.02 & .88 & & & .00 & .00 & -.07 & .59 \\
\hline
\end{tabular}




\section{Figures}

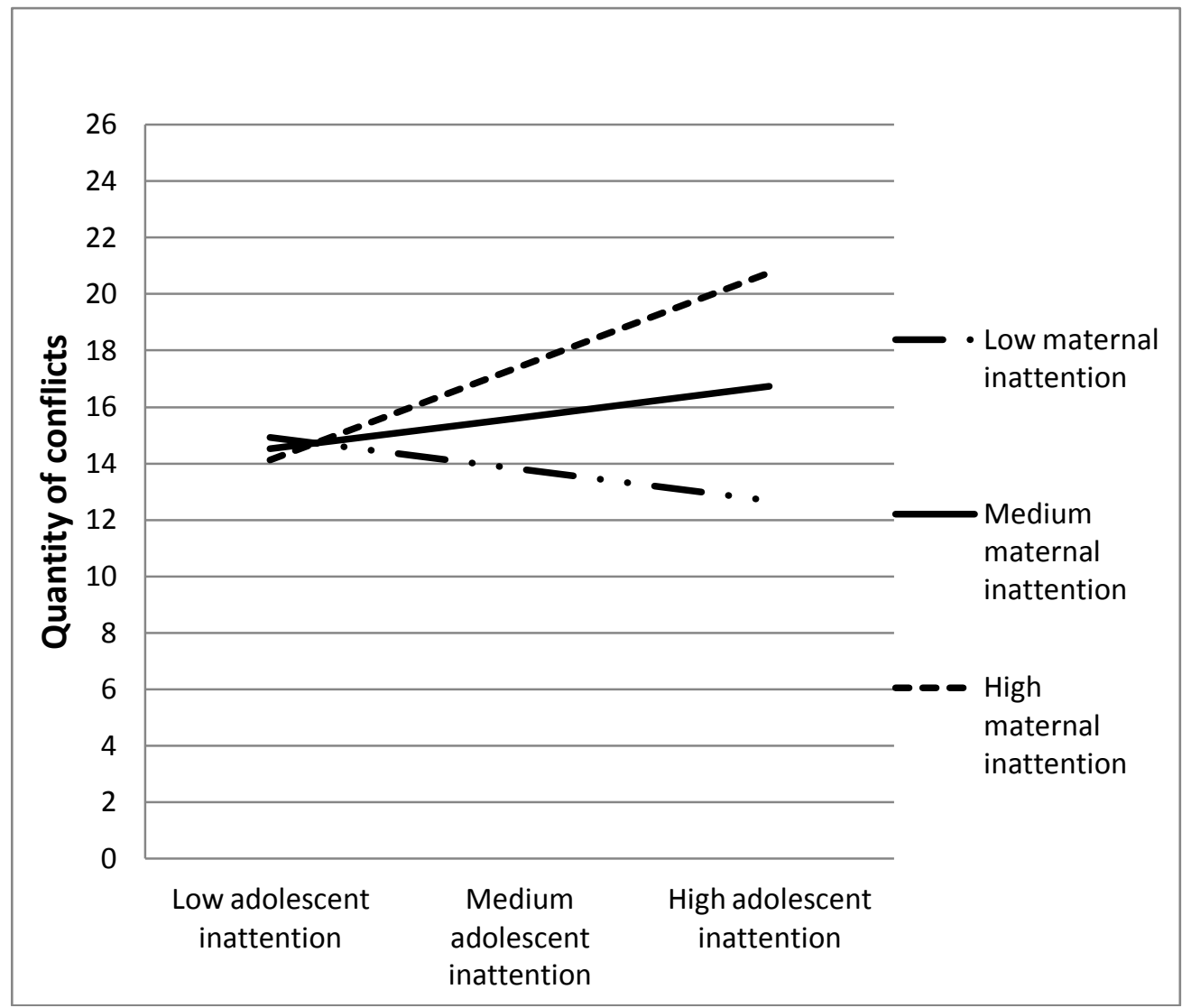

Figure 1. The interaction between adolescent and maternal inattention on conflict quantity. 


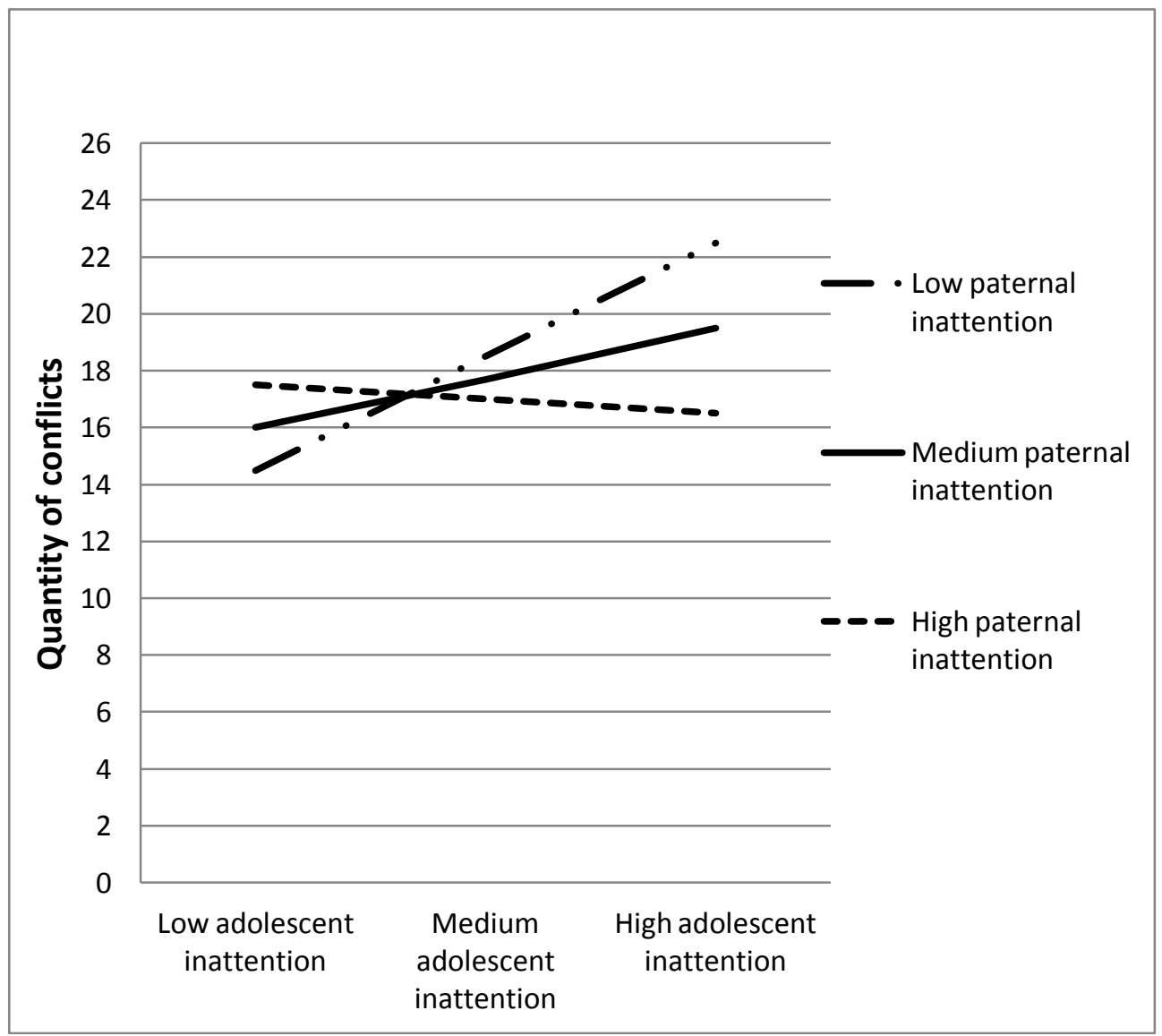

Figure 2. The interaction between adolescent and paternal inattention on conflict quantity. 